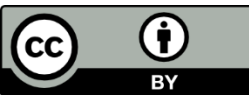

Artículo

\title{
EL TERRORISMO DE ETA Y EL ESPACIO DE LA PERPETRACIÓN: EL CASO DE LA CASA CUARTEL DE VIC
}

DOI: POR ASIGNAR

Dr. Luis Veres Cortés

Universidad de Valencia, Valencia, España.

luis.veres@uv.es

ORCID iD: https://orcid.org/o000-0002-8108-7093

Recibido el 2020-10-26

Revisado el 2021-02-01

Aceptado el 2021-02-01

Publicado el 2021-09-18

\section{Resumen}

Este artículo trata de reflexionar sobre el espacio de la perpetración como elemento comunicativo fundamental en la significación de un atentado terrorista. Para ello, se le considera como elemento fundamental de la significación del texto, centrándose en el caso del atentado de la casa cuartel de la ciudad de Vic perpetrado por ETA el 29 de mayo de 1991.

Palabras clave: ETA, terrorismo, Vic, perpetradores, espacio, persuasión. 


\title{
ETA'S TERRORISM AND THE PERPETRATION SPACE: THE CASE OF VIC'S BARRACKS
}

\begin{abstract}
This article tries to reflect on the space of the perpetration as a fundamental communicative element in the significance of a terrorist attack. For this, it is considered a fundamental element of the meaning of the text, focusing on the case of the attack on the barracks in the city of Vic, perpetrated by ETA on May 29, 1991.
\end{abstract}

Keywords: ETA, terrorism, Vic, perpetrators, space, persuasion. 


\section{Introducción}

La estrategia terrorista de ETA a lo largo de su historia, al igual que la mayoría de los grupos terroristas europeos surgidos en los años sesenta y setenta, se fundamentaba en atentar contra el Estado buscando la repercusión nacional e internacional a través de su impacto en los medios de comunicación (Reinares, 1982; Rodrigo, 1991; Veres, 2017), con el fin de ejercer presión política para la consecución de una exigencia de independencia territorial como nación independiente. Por este motivo, los elementos circundantes del atentado no suponían cuestiones de escasa importancia, sino todo lo contrario, ya que se constituían como entidades generadoras de sentido cuya relevancia semiótica siempre fue importante. Fecha, hora, víctima y espacio del atentado, junto a las circunstancias circundantes de los hechos, cobraban una significación concreta generadora de diversos sentidos que no hay que despreciar desde el punto de vista de la interpretación.

Las fechas suelen ser importantes. Normalmente porque coinciden con un acontecimiento que reúne a las masas, como las olimpiadas de Múnich de 1972, la maratón de Boston en 2013 o la bomba en el Centennial Olympic Park en Atlanta, durante la mitad de un concierto durante su edición de verano. También lo es la hora. Para asesinar al General Luis Carrero Blanco, en 1973, se aprovechó un horario fijo con el que el Jefe del Gobierno de la dictadura franquista acostumbraba a cumplir para asistir a misa. $\mathrm{Y}$ hay que tener en cuenta que la mayoría de los atentados se realizan a primera hora, con el fin de ocupar la agenda informativa de ese día e imponer la noticia, imponer su agenda para indicar que lo más importante es el atentado. Es cierto que se producen atentados en otros horarios, como los sucedidos en Niza o en las Ramblas de Barcelona, pero el motivo residió en la mayor afluencia de personas en dichas horas y en la posibilidad de causar un mayor número de víctimas.

Más visible es la importancia de la elección de la víctima. En este sentido, si atendemos a la elección de las víctimas en un atentado, ésta no resulta nunca casual, ya que el terrorismo tiene mucho de puesta en escena, mucho de dramatización, en donde los elementos relacionados con la imagen y la comunicación, en general, son muy relevantes. En la década de 1970, Brian Jenkins definió el carácter teatral que poseía el terrorismo: los grupos que cometen actos de terrorismo, los "malos tipos", como indica Jenkins, lo hacen, en buena medida, porque buscan el retorno de la repercusión mediática (Hoffman, 1999, p. 62). No se puede hablar, pues, de un terrorismo que se manifiesta discreto, a puerta cerrada, ya que este requiere de demostraciones palmarias y visibles de un poder violento, de una violencia

Perspectivas de la Comunicación - Vol. 14 - No 2 - 2021 - pp. 7-30

Universidad de la Frontera - Chile 
extrema que debe impresionar a los espectadores. Como apunta Fernando Reinares (1990) e Ignacio Sánchez Cuenca (2007) el terrorismo es una violencia armada que busca un efecto psicológico y simbólico que va más allá de los muertos o de los daños materiales. Por eso, las Brigadas Rojas, en la década de los 70, pregonaban la sentencia de "matar a uno para asustar a cien” (p. 53) (pp. 301-319).

Los perpetradores de los atentados son conscientes de esta significación, ya que es ese sentido el objetivo principal de la acción que proporcionará la percepción ansiada de su causa. Las Brigadas Rojas no secuestraron y asesinaron a Aldo Moro por motivos arbitrarios, sino que su crimen respondía a una estrategia simbólica, en parte respaldada por el propio Estado y la Democracia Cristiana y ejecutada por las Brigadas Rojas, pues Aldo Moro, a ojos de los terroristas, había sido el supremo controlador del poder en Italia. Su asesinato no tenía otra función que la de hacer reaccionar a la izquierda italiana respecto a la situación política de su país, imponer "la estrategia de tensión” y evitar la participación del propio Partido Comunista en el gobierno de la república. Por tanto, su asesinato fue muy selectivo (Gotor, 2011; Veres, 2018). Del mismo modo, el grupo terrorista más sangriento de la historia de Europa, ETA, siempre ha elegido concienzudamente sus asesinatos más renombrados: desde Melitón Manzanas o Luis Carrero Blanco hasta Miguel Ángel Blanco o Ernest Lluch. Todos fueron seleccionados buscando la repercusión de los medios y el impacto en la opinión pública. De la misma manera han actuado Al-Qaeda y otros grupos, aunque se trate de atentados indiscriminados como el del Hipercor de Barcelona en 1987, a cargo de ETA, los trenes de Atocha a cargo de Al Qaeda, en 2003, o las explosiones de la maratón de Boston, en 2013. Las Torres Gemelas o la empresa propietaria de Hipercor suponen significaciones variadas, pero tienen en común el simbolismo del poder, contra el que absurdamente muchas veces lucha el terrorismo. La muerte y el miedo tienen su significación. Es cierto que la elección de la víctima puede tener otros fines, pero siempre asociados a esa repercusión. La solvencia en el pago de un secuestro es un motivo que ha propiciado este tipo de crímenes, como el secuestro de Julio Iglesias Puga, padre del cantante Julio Iglesias, por parte de ETA, en diciembre de 1981, o el secuestro del empresario valenciano Luis Suñer, diez meses antes, a cargo del mismo grupo terrorista. Como pone de relieve Aranzadi, ETA, y en general todos los grupos terroristas, atienden con cuidado cada detalle sobre la posible interpretación de sus acciones:

... en algunas teorizaciones etarras (...) ETA se pregunta una y otra vez por el significado de sus acciones amadas, discute incluso si la unidad semántica mínima de la lucha armada es la palabra (cada una de 
las acciones) o la frase (una campaña coordinada de acciones con unidad de intención) especula sobre el papel del entorno y el contexto en la decodificación de sus actos por el pueblo, y patentiza (...) la angustia provocada por la inevitable equivocidad y profunda monstruosidad de todo significante sangriento. (Aranzadi, 1985, p. 230)

Los detalles del atentado se conforman como signos de un universo discursivo que actúa de mediador con los hechos y añade nueva repercusión a la información que se ofrecerá en los medios. Ejemplo de ello se dio con los ataques a la libertad de expresión en Francia, mediante los asesinatos del semanario satírico Charlie Ebdo, el atentado de la sala Bataclán o la decapitación en octubre de 2020 del profesor Samuel Paty por mostrar en clase las caricaturas de Mahoma que años atrás había mostrado la prensa francesa. Se atacaba al modo de vida occidental, la libertad de expresión y la libertad de movimiento, pero se pensaba también en la circulación de ese mensaje hecho de imágenes, crónicas y editoriales a través de la televisión, la radio y la prensa. En todos los casos, se trata de muertes simbólicas cuya función es la de suscitar un imaginario en torno a una causa. Los enemigos de esa causa, con su muerte o sus daños, van a contribuir a forjar esa imagen en donde se va a favorecer cierta dosis de propaganda para la agrupación terrorista. Todo ello sujeto a la valoración de los medios, pero en una situación en que el atentado lanza la consigna de que lo más importante es él y se convierte, por tanto, en el agente que impone la agenda informativa de ese día. El 11 de septiembre, los atentados de Nueva York sobre las Torres Gemelas y en Washington, sobre el Pentágono, no fueron perpetrados para asesinar a 3.000 personas y causar 6.00o heridos, sino para ganarse la audiencia en Estados Unidos desde primera hora de la mañana, de Europa y gran parte de África desde los informativos de mediodía.

Por estos motivos, la valoración del espacio como un elemento generador de información es importante, ya que se encuadra dentro de uno de los elementos del framing de la información. Como indica Entman, el framing se refiere a la preminencia de un aspecto de la información sobre los otros:

una manera de describir el poder de un texto en la comunicación. El análisis de los frames ilumina la manera precisa en que la influencia sobre la conciencia humana es ejercida por el emisor (o por la comunicación) desde un discurso, un enunciado, o desde el noticiario. (...) El Framing esencialmente significa selección y preeminencia (o prominencia, o notabilidad). Hacer un frame es seleccionar algunos aspectos de la realidad percibida y hacerlos más relevantes o notorios en un texto de comunicación, de tal modo que promuevan un particular problema, definición, interpretación, una

Perspectivas de la Comunicación - Vol. 14 - No 2 - 2021 - pp. 7-30

Universidad de la Frontera - Chile 
Esta misma función la ejerce el lugar del atentado como elemento destacado que condiciona notablemente los hechos, y su elección está sujeta a los aspectos simbólicos. Nueva York, Washington o la Estación de Atocha en Madrid se revisten de significaciones diferentes acordes con los propósitos de los perpetradores. Este trabajo pretende reflexionar sobre el papel de la imagen del espacio como elemento de propaganda, como elemento textual y simbólico que pone de relieve el poder de un texto comunicativo" (Entman, 1993, p. 51) y, a su vez, su valor como elemento creador de un imaginario del terrorismo que a veces ha suscitado la ambigüedad y la indefinición. Para ello hemos elegido, por sus peculiares características y su repercusión mediática, el atentado contra la casa cuartel de la Guardia Civil en la ciudad catalana de Vic, acaecido el 29 de mayo de 1991.

\section{ETA y el atentado de Vic}

El terrorismo se ha centrado, a lo largo de su historia, fundamentalmente en tres ámbitos de actuación: el secuestro, la extorsión y el asesinato. Dichas actividades criminales se vinculaban a distintas tipologías espaciales.

El secuestro supone la ruptura de la rutina habitual de la víctima, la privación de libertad y la extracción del sujeto de su espacio vital y su conducción a un encerramiento forzado en condiciones muy duras. ETA acudió a la confección de zulos en pisos o fábricas abandonadas, consistentes en habitáculos de pequeñas dimensiones escondidos tras un tabique o un suelo falso. También realizó secuestros en caseríos y casas retiradas de las grandes ciudades como en el caso de José María Rupérez, destacado político de la Unión de Centro Democrático (UCD), partido al frente de la dirección del país en 1979.

Por su parte, la extorsión implica la extensión del poder de la violencia política del terrorismo de ETA a todo aquel que puede ser fuente de financiación o una amenaza para sus fines. El dinero se convierte en valor de cambio para salvaguardar la propia vida. La carta de extorsión supone una amenaza que extiende el miedo como modo de poder a la víctima y sus familiares (Sáez \& Prieto, 2017, pp. 52-67). Y ese miedo se extiende en el espacio al resto de la población. 
Finalmente, también ETA practicó el asesinato individual o colectivo que se solía producir en la calle. Pero también en bares, en despachos, mediante el disparo directo sobre la víctima o mediante la estrategia del coche con bomba lapa o la carta bomba, casi siempre en un escenario público, como se da en el asesinato de Carrero Blanco en 1973. Por el contrario, las matanzas o intentos de matanzas masivas realizadas por ETA se han repetido en escenarios cerrados, edificios oficiales, domicilios, hoteles, periódicos, pero también en plazas, parques, estaciones de tren o aeropuertos. Hay una casuística recurrente pero no exhaustiva al respecto. En todas esas situaciones el terrorismo busca la repercusión mediática.

Dentro de estos últimos ejemplos se encuentra uno de los más sangrientos atentados del grupo terrorista en España. El 29 de mayo de 1991 se produjo, en la localidad barcelonesa de Vic, la explosión de un coche bomba, cuyo propósito era perpetrar una terrible matanza en la casa-cuartel de la Guardia Civil en esa localidad. La explosión hizo detonar un artefacto de 216 kilos compuesto de 12 bombonas de butano acompañadas de 18 kilos de amonal. El atentado produjo 10 muertos, cinco de ellos niños, y cuarenta y cuatro heridos, la mayoría civiles ${ }^{1}$.

En la casa cuartel sólo residían 14 agentes, motivo por lo que se podía pensar con antelación que la mayoría de las víctimas iban a recaer sobre familiares y visitantes del lugar, dada la capacidad mortífera de los artefactos. A ello se suma la existencia de un colegio religioso ubicado junto al cuartel. El alcalde de Vic, Pere Girbau, reconoció en el documental del periodista Albert Om, Eta o la ciutat dels sants (2011) ${ }^{2}$, la extrañeza de esa elección, ya que "allí no había atentados, porque desde el momento en que teníamos un sentimiento de catalanes, al igual que ellos lo tenían de vascos, ¿por qué tenían que venir a atentar aquí?”3 En el momento del atentado se encontraban jugando en el patio más de cincuenta niños. La matanza podía haber sido mucho mayor, como se reconoce en el documental de David

1 Eco Diario.es. Vic (Barcelona) recordará hoy a las víctimas del atentado de ETA en su casa cuartel. http://ecodiario.eleconomista.es/espana/noticias/1326181/o6/o9/Vic-Barcelona-recordara-hoy-a-las-victimas-delatentado-de-ETA-en-su-casa-cuartel.html. [7-1- 2020].

2 Eta o la ciutat dels sants. España 2011. Dir.: Albert Om. Om, Albert (director). (2011). Eta o la ciutat dels sants [Documental]. España: Televisió de Catalunya - CCMA, Dies Tontos S.L. 3https://www.ccma.cat/tv3/alacarta/programa/Albert-Om-Vic-va-preferir-no-parlar-de-latemptat/video/3447972/

Perspectivas de la Comunicación - Vol. 14 - No 2 - 2021 - pp. 7-30

Universidad de la Frontera - Chile 
Fontseca Mientras los niños jugaban (2011)4, documental en donde se reconstruyen las circunstancias del atentado junto al duelo ciudadano posterior. "Vieron a los críos jugando", reconoce uno de los supervivientes, y "no tuvieron ni la puta vergüenza de decir, es que hay críos”. En el juicio realizado en mayo de 1993, Juan José Zubieta, el único terrorista procesado, ya que los otros dos miembros del comando habían muerto el mismo día de los hechos en un tiroteo con la Guardia Civil, declaró: "ése es un hecho que no valoramos porque no es nuestro problema que los guardias civiles utilicen a los niños como escudos humanos"5. El diario El País dio la información dos meses después, según la cual "la organización terrorista ETA ha ordenado a todos sus comandos que atenten contra las casas cuarteles de la Guardia Civil, aunque en ellas vivan niños, según se detalla en varios documentos elaborados por la banda armada"6. De hecho, la carta que ordenaba la organización de la masacre indicaba: "dar duro y mentalizaros para soportar la presión psicológica”. (Domínguez, 2005, p. 117)

El atentado de la casa cuartel de Vic pone de manifiesto el hecho distintivo de que el terrorismo se diferencia de cualquier otra violencia política mediante la reivindicación comunicativa. El perpetrador terrorista posee una serie de características que lo distingue de cualquier otro criminal, ya que su naturaleza se fundamenta en la reivindicación. La mayoría de los delincuentes esconden sus actos, recurren a alias para no ser conocidos. El perpetrador terrorista llama por teléfono a un periódico para que anuncie su autoría, cuelga vídeos en Internet para propagar su mensaje y atribuirse ese crimen, envía comunicados a la prensa para explicar sus acciones (Veres, 2017). Y ese trabajo reivindicativo se dio tras el atentado de Vic. Primero, porque comunicó su autoría a la prensa y, luego, porque la técnica respondía a la misma estrategia del atentado de la casa cuartel de Zaragoza en diciembre de 1987, con once víctimas mortales, diez de ellas niñas. Por ello, como escribió Sánchez Ferlosio (1982), las muertes provocadas por los terroristas son “muertes firmadas” (p. 79), según una estrategia previa de carácter político planificada y prolongada durante un espacio de tiempo largo, con el fin de subvertir al Estado.

4 Mientras los niños jugaban. España 2011, Dir.: David Fontseca.

5https://www.esdiario.com/206801987/Uxue-Barkos-paga-una-revista-que-homenajea-al-etarra-que-mato-a-5-ninos-enVic.html. [ 8-1-2020].

$6 \mathrm{https} / / /$ elpais.com/tag/juan_carlos_monteagudo/a. [10-1-2020]. 
¿Por qué ese espacio se convirtió en espacio de la perpetración? La casa cuartel de Vic se convirtió en objetivo de ETA, independientemente de la facilidad de perpetración que suponía actuar en una ciudad tranquila de provincias, de la Barcelona más nacionalista, en primer lugar, porque era el hogar de guardias civiles, cuerpo vinculado a la represión franquista en el País Vasco; segundo, por la posibilidad de causar fácilmente daños contra población civil, al actuar en un espacio dentro de la ciudad y provocar una gran cantidad de víctimas que haría más grandes los titulares; $y$, finalmente, porque tras el atentado de la casa cuartel de Zaragoza, el Gobierno se había sentado a negociar y los atentados eran un medio de presión. El atentado seguía la lógica de que "cuando ETA hace sus acciones pretende causar el mayor número de bajas posibles”, como indicó Esteban Nieto, sicario de la banda7. Pero también es cierto que Barcelona es la segunda provincia, fuera del País Vasco, con más atentados (López-Romo, 2015, p. 151) y la matanza se insertaba en una estrategia de acoso contra la Barcelona de las olimpiadas que se iban a celebrar un año después, y que se había iniciado ya en 1987 con el atentado más sangriento de la historia de ETA contra los grandes almacenes de Hipercor en Barcelona. Un año antes se había producido el atentado de Sabadell, en donde murieron seis policías (Domínguez, 2005, p. 83) A ello se une que poco después se celebraba el juicio del caso GAL. Durante el proceso, ETA realizó ocho atentados, lo que otorga a la matanza de Vic el papel de influir en ese juicio. Y la confección del atentado respondió a este propósito y a recomponer sus acciones tras la detención del Comando Barcelona, en 1987. De este modo, se deslizó, con el empuje de los propios terroristas, un vehículo sin freno por la rampa de la puerta lateral del cuartel, en donde, curiosamente, nunca había vigilancia, y con un mando a distancia se hizo detonar el artefacto explosivo. Desde el lugar donde empujaron el coche los terroristas, se veía que había niños jugando en el patio.

\section{El espacio del atentado y la significación}

Con el atentado de Vic, ETA proseguía una estrategia comunicativa basada en la repercusión en los medios, que iba a mantenerse en años siguientes. El caso del concejal del Partido Popular (PP) Miguel Ángel Blanco, asesinado a manos de ETA el 10 de julio de 1997, también resulta singular desde el punto de vista comunicativo. Después de varios días secuestrado,

7 Eta o la ciutat dels sants. España 2011. Dir.: Albert Om. Om, Albert (director). (2011). Eta o la ciutat dels sants [Documental]. España: Televisió de Catalunya - CCMA, Dies Tontos S.L.

Perspectivas de la Comunicación - Vol. 14 - No 2 - 2021 - pp. 7-30

Universidad de la Frontera - Chile 
en los que se le da un ultimátum al gobierno para la liberación de presos de ETA, se le dispara a la cabeza con una bala de poco calibre, no el nueve milímetros parabellum con el que acostumbraba ETA a matar a sus víctimas, sino el cinco milímetros, y ello con el fin de no causar la muerte inmediata y prolongar su agonía y, de este modo, prolongar el relato. Después, se anuncia dónde se encuentra el cuerpo, una cuneta. La policía llega y todavía está vivo. Es conducido al hospital más cercano en donde entra cadáver. Todo el país en vilo, tras un día de manifestaciones. Toda una trama narrativa dividida en episodios. Y el espacio forma parte del componente narrativo del terrorismo en donde se hace temblar la seguridad. Como explica Portinaro (2017), el terrorismo busca "un enorme gueto de inseguridad" (p. 203). En muchos atentados este carácter episódico es evidente. En todos los ejemplos las entregas se suceden en prensa, televisión e internet como un eco de lo noticioso.

Estas ansias de exhibición propias del fenómeno terrorista han propiciado que se compare el terrorismo con el teatro, porque el terrorismo es un teatro con mensaje (Schreiber, 1980, p. 88). Tanto el caso de Vich como el caso del concejal de Ermua lo ponen de relieve. El terrorismo no deja de jugar con la idea del ritual, un ritual en imágenes que forma parte de la sustitución de lo real y que, sin esas imágenes, carece de virtualidad (Baudrillard, 2000, p. 127). El terrorismo juega con la idea del miedo. Ese miedo viene dado por su presencia en los medios. Y el espacio forma parte de ese ritual. Es el fondo de la escena. Como muestran estos dos atentados, la creación de ese miedo pasa por una violencia histórica: la transgresión de los espacios y de los cuerpos, sin el apoyo de los Estados o de las mayorías. Aunque se trate de atentados indiscriminados, como el de Hipercor de Barcelona (1987) o el del Puente de Vallecas (1995), los hechos suponen significaciones variadas, pero poseen en común el simbolismo del poder sobre el espacio y los cuerpos y ese dominio es jurídico, político y simbólico, porque se transgrede la ley, la organización y la libertad, y todo se reconduce por el camino del miedo y la persuasión. Porque ese dominio de la calle, que es propiedad comunal se anula, se transgrede el orden jurídico, se violentan los cuerpos, y esa significación adquiere la finalidad de hacer pensar a otras personas de semejantes características "mañana te puede ocurrir aquí" (Alonso-Fernández, 2002, p. 32). El terrorismo expulsa a los sujetos del ámbito urbano o rural. De este modo, la violencia realiza una transferencia simbólica hacia el espacio y hacia las víctimas, convirtiéndolos en objetos políticos que adquieren una nueva significación. La audiencia entiende así el suceso ubicado en el espacio con un nuevo sentido, así como las víctimas que cobran el valor de un argumento político, un objeto que posee valor de cambio en el juego de la persuasión contra 
el Estado. Y los medios se convierten en garantes de esta semiotización al interferir entre la realidad y el mensaje final percibido.

En el caso del atentado de Vic se conocían perfectamente las posibilidades mortales de la explosión, es más, se buscaba ese propósito con el fin de propagar el miedo, porque "el miedo es el mensaje" (Gil-Calvo, 2003, p. 45), especialmente cuando el objetivo era la Guardia Civil, un cuerpo repetidamente retratado en la propaganda de ETA, en pegatinas y octavillas, como el cuerpo más odiado en el País Vasco, un cuerpo represor del franquismo, formado por gente de fuera del País Vasco, maketos y cipayos, inmigrantes y traidores en euskera. Además, "el cuartel era el lugar seguro en donde dejar a los niños" del vecindario, como declaró uno de los agentes que testifican en el documental Mientras los niños jugaban. Y tampoco la fecha fue casual. Coincidía con la celebración de una prueba ciclista, por lo cual el cuartel estaba escasamente vigilado al estar la mayoría de los agentes en la vigilancia del evento. Se buscó hacer el máximo daño con el fin de ganar la atención mediática.

En el caso de Miguel Ángel Blanco, la estrategia siguió el objetivo de conseguir minutos de televisión y, al mismo tiempo, propagar el terror atentando contra un joven prometedor, líder del PP en el País Vasco. Por ello, la violencia de ETA atentaba contra los cuerpos que son parte de ese espacio de perpetración. Agambem (2010) escribía al analizar el nazismo, que "únicamente en un horizonte biopolítico se podrá decidir, en rigor, las categorías sobre las que se ha fundado la política moderna" (p. 13). Por ello se puede entender que los cuerpos y el espacio son política. Estas entidades no son todas iguales, sino que cada una adquiere un valor simbólico por sí misma, pero también por su naturaleza de carácter político ante la muerte y ante su repercusión mediática. Como indicaba Roland Barthes (1964), al hablar del asesinato, "si es político, es una información, si no lo es, es un suceso" (p. 188), porque el asesinato político necesita un campo de definición y una amplitud definitoria más amplia que el del asesinato corriente. Una nueva esfera de significación, por tanto, aúna nuevos sentidos al significado primario del crimen en sí, una esfera formada por el contexto social e histórico, por la situación del conflicto y sus protagonistas, por sus antecedentes y sus consecuencias. Todo ello está ausente en el asesinato del delincuente ordinario (Veres, 2017, p. 177). La elección de la Casa Cuartel de Vic respondía a la consideración de la casa de la Guardia Civil, por parte del grupo terrorista, como el espacio de una fuerza opresora y una fuerza de ocupación del territorio vasco asociada en la historia a la represión franquista. Hay que recordar que ETA atentó de la misma manera y con los mismos instrumentos en los años de la dictadura que durante la democracia, es más, la mayoría de sus víctimas se produjeron

Perspectivas de la Comunicación - Vol. 14 - No 2 - 2021 - pp. 7-30

Universidad de la Frontera - Chile 
durante el periodo democrático y su subversión contra el estado consistió en considerarse legítima su lucha y su capacidad mortífera. Por ello, la valoración del individuo se ajustaba a lo que Achille Mbembe destaca en el uso del poder social y político para controlar la vida de las personas. Mbembe (2011) va más allá del derecho a matar y explica la realidad de la exposición de las personas a situaciones de riesgo mortal. Su visión de la necropolítica incluye el derecho a poner la muerte social y política de los sujetos como una forma de subyugación, que es lo que Foucault considera fundamento del poder en sí (pp. 19-20). El terrorismo, concretamente el ejercido por ETA en Vic, como la esclavitud o los distintos procesos de depuración, sería una forma de necropoder sobre los cuerpos basada en la asunción como "objetivo de la erradicación de la condición humana fundamental que es la pluralidad" para demostrar la soberanía mediante la lucha a muerte (Mbembe, 2011, pp. 3031). Y también en esa lucha pretendió ganar el espacio y dominarlo. De ese modo, la necropolítica consigue transformar a los seres humanos en una mercancía intercambiable o desechable según dicten sus postulados y el afán de los sujetos en conseguir esa nueva significación. La vida pierde, así pues, toda su densidad y se convierte en una mera moneda de cambio, un objeto que resulta útil para un objetivo para un determinado poder sin escrúpulos.

Esa apertura de la significación y su revestimiento simbólico abarca el espacio de la perpetración que se constituye como el escenario del espectáculo. Normalmente, se trata de lugares visitados, frecuentados, ineludibles, cuya visita es memorable y obligatoria para el visitante y que, además, reúne un gran número de residentes. Además, su reconocimiento como espacio visitable facilita su presencia en los medios cuando la atrocidad se aparece. De ese modo, el espacio se reviste de un nuevo sentido y propicia la creación de memoriales, de monumentos a las víctimas. El terrorismo resemantiza el espacio, incluso a veces lo modifica. Esa consideración del espacio lo asemeja al concepto de "no lugares" designado así por Augé (2000), o al menos a lo que denomina “universos de reconocimiento" (p. 39).

Ese revestimiento simbólico del espacio se produce antes y después de la violencia. A veces el espacio posee una carga simbólica en sí. De ahí su atracción. Esta consideración supone que su elección es premeditada, ya que confiere sentido al atentado y lo convierte en noticioso y en memorable. Pierre Nora, en el prefacio a su primer volumen de Lugares de la memoria, habla de espacios en donde se acumulan testimonios imágenes, "signos visibles de lo que fue", una luz sobre lo que fue y ya no es que se culmina con los memoriales posteriores, todos ellos lugares que plasman "una metáfora de la historia conflictiva de la 
nación" (Winter, 2006, p. 13). Y la estrategia terrorista se fija en este aspecto. El espacio amplió notablemente su esfera de significación al convertirse en signo de la interpretación del atentado que facilita el nuevo simbolismo suscitado por la tanatopolítica sobre los cuerpos.

Con el terrorismo, ETA no ganó totalmente el espacio en el terreno político, pero sí en el terreno simbólico y sólo la memoria de ese espacio y el recuerdo de la masacre puede condicionar el sentido de dicho simbolismo. En muchos casos, el terrorismo de ETA ha optado por el dominio del espacio y la exclusión del cuerpo en las calles. Noëlle-Neumann (1995) habló de "la espiral del silencio" para aquellas situaciones en que el sujeto quedaba aislado por sus opiniones desde el punto de vista comunicativo (pp. 103-109). Y a ese fin respondía el control del espacio. Esa estrategia se fundamenta en la exclusión de personas en determinados espacios, en su estigmatización y aislamiento. Los estados de guerra favorecen frecuentemente estos procesos: desde el genocidio armenio a la limpieza étnica en Bosnia. En una proporción menor, a lo largo de cincuenta años, aproximadamente, la marginación de ciudadanos en el País Vasco formó parte de la estrategia de ETA al apropiarse del espacio público mediante la Kale Borroca o lucha callejera. Muchos ciudadanos del País Vasco fueron inducidos al exilio y a la huida del territorio tras amenazas y a la exigencia del pago del impuesto revolucionario. Porque ETA luchaba por el dominio del territorio y para ello optó por una óptica eliminacionista mediante el miedo, lo que Ariadna Estévez (2018) ha denominado el "dispositivo necropolítico de producción y administración de la migración forzada” (p. 2). De este modo, de 1968 a 2010, ETA fue responsable del $89 \%$ de los asesinatos políticos y del 92 \% de las víctimas causadas por el terrorismo relacionado con el conflicto vasco (López-Romo, 2015, p. 9). Del mismo modo, ETA de 1991 a 2013, realizó 5.113 ataques a empresarios y más de 9.000 empresarios fueron extorsionados (Sáez, 2017, p. 18). ETA extrajo informaciones para atentar sobre más de 15.645 personas, de las cuales aproximadamente 1.000 casos terminaron en imputación judicial (López-Romo, 2015, pp. 103-108). Todo ello suponía una buena razón para muchos ciudadanos para sentirse expulsados y abandonar el territorio.

En esa estrategia, ETA se sirvió también del secuestro para la dominación del espacio. El espacio característico para esta práctica por parte de ETA fue el zulo, que en euskera significa agujero. Ortega Lara fue aislado en un zulo de $2 \times 3 \mathrm{~m}$, como lo fueron en similares circunstancias los secuestrados anteriormente, como Emiliano Revilla (1988) o Cosme Delclaux (1996). Se trataba de lo que Žižek (2009) denominó "la abolición de la dimensión 
del prójimo" (p. 61), en donde el otro era poco más que un objeto. Y en ello había un odio político y, quizás, étnico. Portinaro (2017), siguiendo a Lemkin, define el genocidio como un "plan coordinado de diferentes acciones dirigido a la destrucción de los fundamentos de la vida de un grupo nacional con el objetivo de aniquilarlos" (p. 30). Goldhagen (2010) hablaría en estos casos de un "ataque eliminacionista" (p. 18) o lo que Barth llamaría un "genocidio indirecto" (Portinaro, 2017, p. 34). Claro que las cifras pueden ser menores que en otros conflictos, pero el aislamiento y el reconocimiento del sujeto como no perteneciente a la causa, estrategias presentes en otros contextos, suponían una exclusión progresiva (Alonso, 2018, p. 64), un estigma como escribiría Goffman (2001), de carácter “desacreditador" (p. 13), basado en lo étnico, racial o en la vinculación política, como se detalla en la novela Patria de Fernando Aramburu. El asesinato de Blanco también fue el resultado modélico de este tipo de estigma. En todos los casos, muchos de los que se oponían a ETA resultaban marcados y acababan amenazados, en el exilio, extorsionados o asesinados. Y ese estigma también se refería a la Guardia Civil, como en Vic, lo cual suponía una "exclusión moral” más allá de donde "son aplicables valores y normas" (Otopow, 1990, p. 173).

Alan Wolfe ha advertido que este tipo de apropiación del espacio que conduce a la limpieza étnica es una de las formas más importantes de la maldad política. Para Wolfe (2013, p. 36), esta limpieza consiste en borrar a determinadas personas de un territorio y eliminar cualquier rastro de ellas. Surge así una concepción necropolítica de los individuos que afecta al espacio, una valoración de los individuos como entidades cosificadas, a mitad de camino entre la vida y la muerte, seres con cuyo destino se puede jugar libremente porque sólo la significación del traspaso de la vida a la muerte es importante. Desde el nazismo a la Camboya de los Jemeres Rojos, esa cosificación simbólica del individuo formaba parte del progresivo proceso de destrucción que se incorporaba al lenguaje con toda naturalidad.

Así pues, no resultaba extraño que, como reflejo de la ideología nacionalsocialista para hablar de personas detenidas en un campo de concentración se hablase de piezas, que la utilización del término hombre para referirse a una persona de religión judía resultase siempre irónica y desembocase de manera intencionada en el ridículo. Lo mismo ocurría en el gulag ruso: palabras como querido o humano sólo se utilizaban con sentido irónico o ridículo. Se producía un proceso de cosificación, una cruel alegoría cuyas ramificaciones otorgaban numerosas denominaciones nuevas. A causa de estos hechos se hablaba del aprovechamiento de cadáveres, ya que éstos acababan convertidos en abono para los campos, en tejido confeccionado con los cabellos humanos o en pastillas de jabón a partir de la grasa de los cuerpos; Y nunca los judíos eran asesinados, sino que eran conducidos a la solución final; se 
decía que los miembros de la resistencia eran abatidos, manifestando todo el odio que se ponía en aquellas muertes, o bien se hablaba de que habían sido liquidados, aprovechando un vocablo procedente del lenguaje comercial y cuya razón de ser era el cumplimiento de una deuda. (Veres, 2017, p. 43)

El objetivo de esta estrategia es librarse de estas personas y hacerse con el poder en el territorio que antes ocupaban (Wolfe, 2013, p. 36). Y detrás de todo ello, según Michael Mann (2004), muchas veces se mantiene una radicalización del nacionalismo o del etnocentrismo, en donde la raza se impuso a la clase, (p. 107). Christian Scherrer (2005) estableció diversas fases en el desarrollo de una tanatopolítica que conduce a su fase final que es el genocidio. Entre esas fases se incluye el reconocimiento, el aislamiento de la víctima, su deshumanización, el control y la atrocidad antes de su exterminio parcial (p. 8), es decir, se da obligatoriamente su aislamiento en el espacio para su posterior aniquilación en ese lugar. Se impuso una persecución basada en una derivación del etnicismo presente en la obra de Sabino Arana que despreciaba lo español a favor de una visión imaginaria de lo vasco (Juaristi, 1997, 2001; Pablo, Meers \& Rodríguez-Ranz, 2001; Aranzadi, Juaristi \& Unzueta, 1994), cuestión que se ha manifestado con recurrencia en declaraciones de miembros de ETA:

\footnotetext{
Te dabas cuenta de que, joder, de que tú no eras español. Así de claro. Decías, pero yo ¿̇qué chorra tengo que ver con los de Segovia, por ejemplo? Y no tengo nada en contra con los de Segovia. Pero yo es que me daba cuenta de que... decimos ipero si es que es imposible! iSomos totalmente distintos! $\mathrm{Ni}$ comemos, ni dormimos, ni nuestros excrementos son iguales. El idioma es distinto. Y yo decía, bueno, si yo veo a diez personas o a cien personas en la playa desnudas, yo no tengo ni idea quiénes son hasta que me hablan. Cuando hablan, digo, joder, pues son ingleses o son lo que sea. Entonces a mí que no me digan que soy igual que uno de Andalucía, porque yo no soy igual, joder. Mis genes tienen que ser de otra forma. (Reinares, 2001, pp. 163-164)
}

En esta estrategia del dominio del espacio, ETA consideró que era importante la presión sobre la víctima. ETA, al igual que lo hiciera el IRA o las Brigadas Rojas, creó toda una estética callejera de banderas, proclamas, pintadas, amenazas, lemas e imágenes de terroristas que significaban el dominio del territorio. Había presión en los bares, en las calles, en las escuelas, en las instituciones. La apropiación del espacio resultaba de este modo fundamental en la estrategia terrorista, y cuanto mayor sea, mayor es el logro. ETA, y su brazo político Batasuna, dominaron la calle en los años 90 y 2000, y organizaron una infraestructura que se hizo con una parte del espacio público, tanto rural como urbano. La exclusión del contrario llevó a un dominio de todo espacio al llegar a ser el único segmento 
social de izquierda con presencia en ciudades y pueblos mediante marchas por la paz, que eran elogios de la violencia y homenajes a presos de ETA y a asesinos huidos:

\begin{abstract}
El entramado civil de la banda se fue ampliando posteriormente con la aparición o apropiación de empresas deportivas, educativas y culturales (determinadas ikastolas, academias de enseñanza del Euskera, editoriales, sellos discográficos, radios, etc.), su expansión en el mundo asociativo, su influencia en la universidad, una extensa red de herrico tabernas (tabernas del pueblo), la promoción del rock radical vasco, el cuasi monopolio de las fiestas populares en donde se repartía propaganda, etc. Apareció entonces una sociedad dentro de la sociedad, con su propia cultura, sus redes sociales, sus medios de comunicación, sus lugares de ocio, sus rituales, su vestimenta, sus claves internas, su argot, etc. En definitiva, se trataba de una comunidad incivil. (Fernández-Soldevilla \& López-Romo, 2017, p. 145)
\end{abstract}

El entorno de ETA, entendido éste, no como meros simpatizantes ideológicos, sino como colaboradores activos, muchas veces a sueldo se servía de canales propagandísticos como para transmitir su narrativa en donde destacaban los lugares de socialización como bares, conciertos, fiestas populares. Se destacaba lo diferencial y aquellas enseñas que hicieran referencia al conflicto vasco. Así se apelaba a la ocupación histórica del Estado para justificar los atentados.

Homenajes en la calle, celebraciones con banderas, pintadas, suponen la apropiación del espacio y la exclusión de los sujetos que en muchos casos comportan una discriminación racial, social o política. La falta de condena de la violencia y una memoria igualadora de todas las víctimas también conducen a esta exclusión y a evitar el perdón (Mate, 2008, p. 41). Y eso se hizo en muchos casos con un apoyo explícito, si no a la violencia del terrorismo, sí a lo que el terrorismo representaba (López-Romo, 2015, p. 117). Como señala Gaizka Fernández (2016), fueron frecuentes en el entorno de ETA los homenajes a perpetradores de asesinatos fallecidos. Jesús Casquete (2009) advierte que se fue construyendo un calendario en donde se acumulaban conmemoraciones y aniversarios de este tipo. Especial relevancia tenían los homenajes a miembros históricos como Txabi Etxebarrieta o Pertur, muerte de este último que sigue sin esclarecerse al existir sospechas sobre sus propios compañeros de lucha armada. Sus fotografías en blanco y negro quedaron estandarizadas en las décadas siguientes, íconos cuya estética se generalizó a gran número de presos.

La saga patriótica era una tupida red narrativa entretejida con diferentes episodios, liturgias y símbolos, los más importantes de los cuales eran los propios miembros de ETA. Así, la izquierda abertzale empezó 
a rendir un auténtico culto a sus gudaris 8 : a los etarras muertos se los elevaba a la categoría de mártires cuya memoria había que honrar periódicamente; a los presos (estimados como presos políticos, ya que el fin superior les absolvía de los medios empleados) se les recibía como auténticos héroes nacionales cuando salían de la cárcel; a los que continuaban en activo se les cedió la representatividad del movimiento y se les reconoció el poder de la infalibilidad: si asesinaban a una persona era porque esta era culpable (algo habrán hecho). (Fernández-Soldevilla, 2013, p. 77)

Ejemplo evidente de este fenómeno social fue el mismo entierro de Jon Erezuma, miembro del comando Barcelona y responsable del atentado de Vic, que fue detenido al día siguiente de este hecho y conducido a Guernica, su ciudad natal. Allí fue recibido su féretro como el de un héroe nacional, entre flores y banderas, como recuerda el documental de Albert Om y también el de David Fontseca. Estas imágenes apuntan al gran apoyo de parte de la población que, en casi todos los casos, fue definitivo para el control del espacio. Desde la designación del enemigo como maketo a proclamas como "para amar el euskera, tenéis que odiar a España” (Fernández-Soldevilla \& López-Romo, 2017, p. 43). Los dos atentados aquí tratados respondían a esa estrategia de expandir el miedo para hacerse con el espacio.

Muchos espacios se han convertido en lugares de la memoria del terrorismo y mediante su soporte material se han confirmado como una estructura textual. Los vínculos de esta realidad con el caso de Vic son tratados en el documental de Albert Om ETA o la ciutat dels sants (2011), en donde se recoge la historia del atentado en relación con el vuelco inicial de los habitantes de Vic con las víctimas y su paulatino olvido. En el caso de la casa cuartel de Vic, las autoridades propusieron la construcción de un memorial que recordase los hechos acaecidos allí y el recuerdo de las víctimas. Pero primaron los intereses económicos o, simplemente, los deseos de olvidar. "No tenían familiares aquí", dice uno de los testigos en el documental. Esta actitud pone nuevamente de relieve esta estrategia necropolítica en que los sentimientos hacia el otro quedan anulados en un proceso de despersonalización gradual en mayor o menor grado. Tras el atentado, y prueba de ello es esta marca en la memoria, el cuartel no se reconstruyó y tiempo después, los comerciantes del mercado próximo proyectaron la construcción de un aparcamiento que se llevó a cabo9 ${ }^{9}$. Años después, el ayuntamiento decidió construir una biblioteca. En el lugar no hay nada que rememore lo

8 "Soldados" en euskera. El nacionalismo vasco siempre ha hablado de gudaris en sentido heroico.

9https://web.archive.org/web/20100902024956/http://terranoticias.terra.es/articulo/html/av225730.htm. [7-1- 2020].

Perspectivas de la Comunicación - Vol. 14 - No 2 - 2021 - pp. 7-30

Universidad de la Frontera - Chile 
sucedido excepto una placa de $40 \times 60 \mathrm{~cm}$ que no recuerda los hechos, sino que presenta un lema, al menos, ambiguo: "En recuerdo de todas las víctimas del terrorismo", de modo que se ha borrado prácticamente el acontecimiento de la memoria o se ha cambiado su sentido, teniendo en cuenta que uno de los verdugos del comando Barcelona había sido dirigente de la organización terrorista Terra Lliure. Las pintadas nacionalistas se solapan sobre la placa. Además, hay que tener en cuenta que en Vic nunca hubo una manifestación contra ETA. Sí la hubo para que no se colocara más una casa cuartel junto a un colegio, lo cual forjó un mensaje confuso. Las primeras gestiones para la confección de algún tipo de recuerdo se realizaron en los años 92 y 93, a cargo de Roberto Manrique, delegado en Cataluña de la Asociación de Víctimas del Terrorismo, y las autoridades lo vieron como un signo de que "el españolismo quiere entrar aquí”, como advierte el periodista Miquel Macià en el documental de Om. El primer homenaje se realizó dieciocho años después, en 2009, algo que resulta un tanto sorprendente. Pero el atentado tuvo sus consecuencias en la memoria de la ciudad y en el mundo del nacionalismo. Año y medio después se disolvía el grupo terrorista Terra Lliure. El documental de Om, de manera sagaz, plantea una pregunta interesante en torno a este recuerdo: ¿Se hubiera reaccionado igual si la bomba se hubiera colocado en la plaza principal de Vic en lugar de en un cuartel de la Guardia Civil? Y la respuesta es: posiblemente, no. La pregunta nos replantea la función simbólica del espacio y su relación con la memoria de los hechos violentos. Jordi Pujol, presidente del gobierno autónomo catalán, la Generalitat de Catalunya, en esos años, manifiesta en dicho documental que le "gustaría creer que no, que no hubiera sido diferente la reacción de la población, pero que el atentado indudablemente hubiera sido diferente porque ese iba contra la Guardia Civil”.

El caso de Miguel Ángel Blanco es totalmente diverso en este sentido. La repercusión del atentado fue mucho mayor. Supuso un cambio en la estrategia de ETA y en la percepción del terrorismo por parte de la población en toda España. El nombre de Miguel Ángel Blanco designa a una fundación que dirige su propia hermana y que está muy vinculada al Partido Popular, al cual pertenecía la víctima. Miguel Ángel Blanco tiene monumentos y placas en memoria de su persona en Madrid, Mérida, Alicante, Santander, Orense, Jérez, Logroño, Barakaldo, Ermua y muchos más sitios, entre otras razones porque el propio Partido Popular las ha promovido desde los ayuntamientos que dirige, cuestión comprensible desde el punto de vista de la propaganda, pero reprobable en cuanto a la explotación del ícono víctima, que también supone una apropiación del espacio, es cierto, pero de calibre mucho menor y sin recurso a la violencia. Blanco ha sido una víctima rentable al Partido Popular que ha explotado el tema de las víctimas hasta el punto de que colectivos de víctimas, como 
COVITE, han llamado la atención sobre el asunto, acusando al Partido Popular de "banalizar" el terrorismo y de utilizarlo en su favor con frivolidad ${ }^{10}$. Una cosa es el recuerdo y otra es aprovecharse de manera vergonzante, interesada e impúdica de las víctimas, mediante la repetición continua de los secuestrados, asesinados, extorsionados y forzados al exilio, como lo hizo el partido ultraderechista VOX el 21 de octubre de 2020, en la moción de censura en el parlamento español al presidente del gobierno Pedro Sánchez. La mejor manera de hacer justicia a las víctimas es tratarlas de manera humana y no haciendo de ellas objetos simbólicos que también suponen una apropiación del sentido de los lugares de la memoria.

Otra razón para esa cantidad de memoriales sobre Miguel Ángel Blanco reside en el propio patetismo del atentado y su repercusión mediática, ya que la noticia dio la vuelta por todo el mundo, y ello ha marcado en mayor medida la memoria, pero también el aprovechamiento político. Y frente a ello, el atentado de Vic, cuya población reaccionó en ayuda de las víctimas muy rápidamente, pero luego prefirió echar adelante y olvidar. Las imágenes han quedado en la memoria, pero también su olvido sobre el espacio en donde se realizó el atentado. Como estableció Bachelard (1965), "las grandes imágenes tienen a la vez una historia y una prehistoria. Son siempre a un tiempo, recuerdo y leyenda. No se vive nunca la imagen en primera instancia. Toda imagen grande tiene un fondo onírico insondable y sobre ese fondo del pasado personal pone sus colores peculiares.” (p. 64). Y esos colores peculiares, es decir, su posibilidad de recuerdo fue cercenada en el caso de Vic.

Los detalles de esta situación plantean cierto desbarajuste que supone la consideración de víctimas de distinto nivel y también la pérdida del recuerdo de la víctima. Se trata de la desaparición de la mirada de la víctima que conduce a la exclusión y a una nueva alternativa en la construcción del relato. La usencia del recuerdo de las víctimas supone la exclusión de un hecho mítico y, como aclara Richard Slotkin, el mito es el lenguaje con el que un pueblo recuerda su historia (Faery, 1999, p. 15), el espacio, redesignado, con referentes transformados en ese atentado que es un acto de semiotización ya de por sí, adquiere un nuevo sentido al servicio de la memoria o del olvido, dependiendo de los intereses concretos

10 https://www.rtve.es/noticias/20191210/espinosa-monteros-sobre-alvarez-toledo-quiza-no-tenga-empatia-seria-deseablevictimas-del-terrorismo/1993435.shtml 
de una causa política. Muchos miembros de ETA siguen sin condenar aquella violencia política y, por ello, la anulación de ese espacio de la memoria, el espacio de Vic supone la renuncia a una exigencia y necesidad de verdad y reparación por parte de las víctimas que expliquen quiénes fueron los verdugos, por qué perpetraron la matanza, por qué se eligió ese objetivo y no otro. Como sugiere Enzo Traverso (2005), estas situaciones significan una renuncia a la historia y al conocimiento del sufrimiento de las víctimas (pp. 9-20). Y esa mirada excluida también ha sido un elemento configurador de la geografía espacial, que propicia, donde debía preservarse la memoria, el reconocimiento o la restauración del daño, un tremendo olvido de donde no se desprende ningún consuelo.

\section{Conflicto de interés:}

"Los autores declaran que no existen conflicto de interés". "Los financiadores no han tenido ningún rol en: el diseño del estudio; la recolección, análisis o interpretación de los datos; en la escritura del manuscrito, o en la decisión de publicar los resultados.” 


\section{Referencias bibliográficas}

AGAMBEN, G. (2010): Homo sacer. El poder soberano y la nuda vida. Valencia, Pre-Textos.

ALONSO, R. (2018): La derrota del vencedor. La política antiterrorista del final de ETA. Madrid, Alianza Editorial.

ALONSO-FERNÁNDEZ, F. (2002): Fanáticos terroristas. Claves psicológicas y sociales del terrorismo. Barcelona, Salvat.

ARANZADI, J. (1985): Sangre simbólica. Raíces semióticas de la violencia etarra. Ideas y debate, (2), p. 230.

ARANZADI, J., JUARISTI, J. \& UNZUETA, P. (1994): Auto de Terminación. Madrid, El País-Aguilar.

AUGÉ, M. (2000): Los no lugares. Espacios del anonimato. Una antropología de la sobremodernidad. Barcelona, Gedisa.

BACHELARD, G. (1965): La poética del espacio. México, Fondo de Cultura Económica.

BARTHES, R. (1964): Essais critiques. Paris, Seuil.

BAUDRILLARD, J. (2000): Pantalla total. Barcelona, Anagrama.

CASQUETE, J. (2009): En el nombre de Heuskal Herria. La religión política del nacionalismo vasco radical. Madrid, Tecnos.

DOMÍNGUEZ, F. (2015): ETA en Cataluña. Madrid, Temas de Hoy.

ENTMAN, R. (1993): Framing. Toward clarification of a fractured paradigm. Journal of Communication, 43(4), pp. 51-58. https://doi.org/10.1111/j.14602466.1993.tbo1304.x 
ESTÉVEZ, A. (2018): El dispositivo necropolítico de producción y administración de la migración forzada en la frontera Estados Unidos-México. Estudios Fronterizos, 19. https://doi.org/10.21670/ref.1810010

FAERY, R. (1999): Cartographies of Desire. Captivity, Race and Sex in the Saphing in American Nation. Norman, University of Oklahoma Press.

FERNÁNDEZ-SOLDEVILLA, G. \& LÓPEZ-ROMO, R. (2017): Sangre, votos, manifestaciones: ETA y el nacionalismo vasco radical 1958-2011. Madrid, Tecnos.

FERNÁNDEZ-SOLDEVILLA, G. (2013): Héroes, heterodoxos y traidores. Historia de Euskadiko Ezkerra. Madrid, Tecnos. (2016): La voluntad del gudari. Madrid, Tecnos.

GIL-CALVO, E. (2003): El miedo es el mensaje. Riesgo, incertidumbre y medios de comunicación. Madrid, Alianza Editorial.

GOFFMAN, E. (2001): Estigma. La identidad deteriorada. Buenos Aires, Amorrortu Editores.

GOLDHAGEN, D. J. (2010): Peggio della guerra. Lo sterminio di masa nella storia dell'umanità. Milán, Mondadori.

GOTOR, M. (2011): Il memoriale de la Repubblica. Torino, Einaudi.

HOFFMAN, B. (1999): A mano armada. Historia del terrorismo. Madrid, EspasaCalpe.

JUARISTI, J. (1997): El bucle melancólico. Historias de nacionalistas vascos. Madrid, Espasa-Calpe. (2001): El bosque imaginario. Madrid, Suma de Letras.

LÓPEZ-ROMO, R. (2015): Informe Foronda. Los efectos del terrorismo en la 
sociedad vasca. Madrid, Catarata.

MANN, M. (2004): El lado oscuro de la democracia. Valencia, Publicaciones de la Universidad de Valencia.

MATE, R. (2008): Justicia de las víctimas. Terrorismo, memoria, reconciliación. Barcelona, Anthropos.

MBEMBE, A. (2011): Necropolítica. Santa Cruz de Tenerife, Melusina.

NOËLLE-NEUMANN, E. (1995): La espiral del silencio. Barcelona, Paidós.

OTOPOW, S. (1990): Moral exclusion and injustice: An introduction. Journal of Social Issues (46), pp. 173-182.

PABLO, S., MEES, L. \& RODRÍGUEZ-RAN, J. A. (2001): El péndulo patriótico. Historia del Partido Nacionalista Vasco II (1936-1979). Barcelona, Crítica.

PORTINARO, P. (2017): L’imperativo di uccidere. Roma, Laterza.

REINARES, F. (Comp.) (1982): Terrorismo y sociedad democrática. Madrid, AKAL. (1990): Sociogénesis y evolución del terrorismo en España, en S. Giner (Dir.), España. Sociedad y Política (pp. 353-396). Madrid, Espasa-Calpe. (2001): Patriotas de la muerte. Madrid, Taurus.

RODRIGO, M. (1991): Los medios de comunicación ante el terrorismo, Barcelona, Icaria.

SÁEZ, I. \& PRIETO, J. (2017): La extorsión como proceso social en un contexto de violencia terrorista, en I. Sáez (Ed.), Misivas del terror. Madrid, Marcial Pons.

SÁEZ, I. (Ed.) (2017): Misivas del terror. Análisis ético-político de la extorsión y la violencia de ETA contra el mundo empresarial. Madrid, Marcial Pons. 
SÁNCHEZ-CUENCA, I. (2007): Terrorismo, en R. Zapata-Barrero (Ed.), Conceptos políticos en el contexto español. Madrid, Síntesis.

SÁNCHEZ-FERLOSIO, R. (1982): Notas sobre el terrorismo, en F. Reinares (Comp.), Terrorismo y sociedad democrática. Madrid, Akal.

SCHERRER, C. (2005): Genocide and Mass Violence in the 2oth and 21st Centuries. An Introdution: Critera, Common Elements, and Patterns. Moers, IFEK.

SCHREIBER, J. (1980): La última arma: terrorismo y orden mundial. Zaragoza, Trazo Editorial.

TRAVERSO, E. (2005): Los judíos y Alemania. Valencia, Pre-Textos.

VERES, L. (2017): Los lenguajes del terrorismo. Valencia, Tirant lo Blanc. (2018): Las Brigadas Rojas y el cine. Valencia, Tirant lo Blanc.

WINTER, U. (2006): Lugares de memoria de la Guerra Civil y el Franquismo. Madrid, Iberiamericana-Vervuert.

WOLFE, A. (2013): La maldad política. Barcelona, Galaxia Gutemberg.

ŽIŽEK, S. (2009): Sobre la violencia. Barcelona, Paidós. 